\title{
Major Place Harmony in ABC and the (Reduced) Role of Representation: Evidence from Ngbaka
}

\author{
Nick Danis \\ Rutgers University
}

\section{Introduction}

In existing surveys of long-distance consonant harmony, no instances of major place harmony have been found (Shaw 1991, Hansson 2010, Rose \& Walker 2004, Bennett 2013). In such a case, the agreeing feature between two segments is any of [coronal], [dorsal], or [labial].

Ngbaka (Ubangi, Democratic Republic of the Congo, [nga]) contains several consonant co-occurrence restrictions in roots between labials, dorsals, and labial-dorsals. These patterns are best analyzed as a case of long-distance major place harmony, a process which is otherwise unattested. The relevant processes, along with an additional restriction on voicing, are listed below: ${ }^{1}$

(1) Place Agreement on Labials
a. $* \mathrm{P} \ldots \widehat{\mathrm{KP}}$
b. $* \overparen{\mathrm{KP}} \ldots \mathrm{P}$

(2) Place Agreement on Dorsals
a. $* \mathrm{~K} \ldots \widehat{\mathrm{KP}}$
b. $\sqrt{\mathrm{KP}} \ldots \mathrm{K}$

(3) Voicing Agreement
a. $*$ T...D
b. ${ }^{*} \mathrm{D} \ldots \mathrm{T}$

These processes are supported by a new statistical analysis of a Ngbaka dictionary, Maes 1959, discussed in Section 3, and analyzed within the framework of Agreement by Correspondence (ABC, Hansson 2010, Rose \& Walker 2004, Bennett 2013, a.o.). For Place Agreement on Labials (PAL), labials correspond, and agree for place. Likewise for Place Agreement on Dorsals (PAD), except for a subset of dorsals: only pairs of the form K... KP correspond and agree for place. Finally, Voicing Agreement (VA) demands all homorganic oral stops correspond and agree in voicing. The representation of complex segments is simplified as asymmetries between [labial] and [dorsal] are now captured via the constraint ranking and definitions (cf. Sagey 1986).

\section{Background and definitions}

The language investigated is Ngbaka, iso code [nga] (Maes 1959, Henrix, Eynde \& Meeuwis 2007). This language is related to but distinct from Ngbaka ma'bo (Ubangi, Central African Republic, [nbm]) (Lewis 2009), which is described in Thomas 1963 and analyzed in Sagey 1986, Mester 1986, Rose \& Walker 2004, among others (referred to there as simply Ngbaka). Walker 2001 specifically analyzes voicing agreement in Ngbaka ma'bo, focusing on homorganic stops. For the purposes of the argument here, Ngbaka and Ngbaka ma'bo both contain PAL and therefore major place harmony.

Crucial in describing these processes are the notions of homorganicity, heterorganicity, and a newlydefined relation of semihomorganicity. They are defined as follows, where S1 and S2 are segments and Place(S) refers to the set of place features for S:

$$
\begin{aligned}
& \text { a. } \text { Homorganicity } \\
& \text { Place }(\mathrm{S} 1)=\operatorname{Place}(\mathrm{S} 2)
\end{aligned}
$$

\section{b. Heterorganicity Place $(\mathrm{S} 1) \cap$ Place $(\mathrm{S} 2)=\varnothing$}

\section{c. Semihomorganicity Place $(\mathrm{S} 1) \subsetneq$ Place $(\mathrm{S} 2)$}

\footnotetext{
* Thanks to Akin Akinlabi, Will Bennett, and Alan Prince for comments, and to Paul de Lacy and Dana Matarlo for making data collection possible. I would also like to thank the audience at AMP and my colleagues at Rutgers, whose comments were extremely helpful. All mistakes are my own.

1 Throughout this paper, all double articulations are represented with a tie-bar (e.g. [kp] $)$ and prenasalization is represented with a superscripted nasal (e.g. $\left.\left[{ }^{\mathrm{m}} \mathrm{b}\right]\right)$. There are no clusters considered here; all forms are single segments.
} 
Homorganic segments have equal sets of place features, and heterorganic segments have zero shared place features. However, complex segments can have both shared and unshared place features with a simple segment; this relationship is called here semihomorganicity and is defined using the proper subset relation. ${ }^{2}$

\section{Dictionary analysis}

As empirical support, Maes's Dictionnaire Ngbaka-Francais-Neerlandais was digitized and converted into a searchable database. Words were coded for the place of articulation for both consonants, in addition to their voicing and manner. Summaries of the results for Observed (O), Expected (E), and significance for the relevant combinations are shown in Tables 1 and 2. Definitions for the place and manner abbreviations are given in (5-6). Homorganic coronal and labial pairs appear as expected. Homorganic labial-dorsal pairs $(\widehat{\mathrm{KP}} \ldots \widehat{\mathrm{KP}})$, however, are significantly overrepresented. All semihomorganic pairs are significantly underrepresented, except for $\widehat{\mathrm{KP}}$...K pairs, which appear as expected.

Table 1: Summary of place restrictions for all homorganic and semihomorganic pairs

\begin{tabular}{ccccll}
\hline Combination & $\mathrm{O}$ & $\mathrm{E}$ & $\mathrm{O} / \mathrm{E}$ & Significance & Result \\
\hline $\mathrm{C} \ldots \mathrm{C}$ & 28 & 28.36 & 0.99 & $p=1$ & As expected \\
$\mathrm{P} \ldots \mathrm{P}$ & 12 & 16.06 & 0.75 & $p=0.31$ & As expected \\
$\mathrm{K} \ldots \mathrm{K}$ & 26 & 39.25 & 0.66 & $p=0.00630$ & Underrepresented? \\
$\mathrm{KP} \ldots \mathrm{KP}$ & 11 & 3.62 & 3.04 & $p<0.00625$ & Overrepresented \\
\hline $\mathrm{P} \ldots \widehat{\mathrm{KP}}$ & 0 & 6.39 & 0.00 & $p<0.00625$ & Underrepresented \\
$\mathrm{KP} \ldots \mathrm{P}$ & 2 & 9.09 & 0.22 & $p<0.00625$ & Underrepresented \\
$\mathrm{K} \ldots . . \mathrm{KP}$ & 1 & 8.49 & 0.12 & $p<0.00625$ & Underrepresented \\
$\mathrm{KP} \ldots \mathrm{K}$ & 13 & 16.71 & 0.78 & $p=0.32$ & As expected \\
\hline
\end{tabular}

Table 2: Summary of voicing and nasal restrictions for all homorganic pairs

\begin{tabular}{ccccll}
\hline Combination & $\mathrm{O}$ & $\mathrm{E}$ & $\mathrm{O} / \mathrm{E}$ & Significance & Result \\
\hline $\mathrm{T} \ldots \mathrm{D}$ & 0 & 5.10 & 0.00 & $p<0.0167$ & Underrepresented \\
N... ${ }^{\mathrm{N}} \mathrm{D}$ & 1 & 2.32 & 0.43 & $p=0.47$ & As expected \\
$\mathrm{D} \ldots{ }^{\mathrm{N}} \mathrm{D}$ & 8 & 7.19 & 1.11 & $p=0.67$ & As expected \\
\hline
\end{tabular}

3.1 Methodology Maes 1959 was chosen as the dictionary for analysis as it contains Ngbaka headwords first, and in near-IPA. Both of these aspects ease the task of eventual parsing. The physical dictionary was scanned and run through OCR software (Abbyy FineReader), looking for French, Dutch, and speciallytrained IPA characters. After this, the resulting text file was hand-checked against the original dictionary, ensuring accuracy for all Ngbaka consonant and vowels (tone and nasal diacritics may still be inaccurate). Once checked, the data was parsed into an SQL database, where it could be annotated and searched. ${ }^{3}$

All biconsonantal words $(n=880)$ were extracted from the full list. This ensures enough consonants to see a co-occurrence restriction, and rules out most reduplicated and morphologically complex words, where the restrictions may not apply. Oral and nasal stops were sorted by place of articulation: ${ }^{4}$

$$
\begin{aligned}
\operatorname{cor}(\mathrm{C}) & =\left\{\mathrm{n},{ }^{\mathrm{n}} \mathrm{d}, \mathrm{d}, \mathrm{t}, \mathrm{d}\right\} \\
\operatorname{dor}(\mathrm{K}) & =\left\{\mathrm{n},{ }^{\mathrm{g}}, \mathrm{g}, \mathrm{k}\right\} \\
\operatorname{lab}(\mathrm{P}) & =\left\{\mathrm{m},{ }_{\mathrm{m}} \mathrm{b}, \mathrm{b}, \mathrm{p}, 6\right\} \\
\text { lab-dor }(\mathrm{KP}) & =\left\{\widehat{\mathrm{mm}},{ }^{\mathrm{jm}} \mathrm{gb}, \widehat{\mathrm{gb}}, \widehat{\mathrm{kp}}\right. \\
\text { other } & =\text { all non-stops }
\end{aligned}
$$

2 If glottals are assumed to be placeless, then we might want to rule out trivial semihomorganicity (e.g. between [t] and [?]) by stipulating that $\operatorname{Place}(\mathrm{S} 1) \neq \varnothing$.

3 Thanks to Dana Matarlo and Paul de Lacy for help with this part of the project.

4 Certain numbers may differ slightly from the presented version, as implosives were not included in those totals. 
To test for voicing and nasality restrictions, summarized in Table 2, each consonant pair was tagged as either homorganic or non-homorganic (heterorganic and semihomorganic), and individual consonants as voiced stops, voiceless stops, nasals, or prenasalized stops.

$$
\begin{aligned}
\text { voiceless stops }(\mathrm{T}) & =\{\mathrm{t}, \mathrm{p}, \mathrm{k}, \widehat{\mathrm{kp}}\} \\
\text { voiced stops }(\mathrm{D}) & =\{\mathrm{d}, \mathrm{b}, \mathrm{g}, \widehat{\mathrm{gb}}\} \\
\text { nasals }(\mathrm{N}) & =\{\mathrm{n}, \mathrm{m}, \mathrm{y}, \widehat{\mathrm{gm}}\} \\
\text { prenasalized stops }\left({ }^{\mathrm{N}} \mathrm{D}\right) & =\left\{{ }^{\mathrm{n}} \mathrm{d}, \mathrm{m}_{\mathrm{b}},{ }_{\mathrm{g}}^{\mathrm{g}},{ }^{\mathrm{gm}} \widehat{\mathrm{gb}}\right\}
\end{aligned}
$$

Observed (O), Expected (E), and $\mathrm{O} / \mathrm{E}$ ratios are calculated for all place combinations. Expected values are calculated following Pierrehumbert 1993, Frisch 2011, and they are defined as follows:

$$
\begin{aligned}
& O=\text { observed }\left(C_{1}, C_{2}\right) \text { forms in lexicon } \\
& E=\frac{\operatorname{Obs}\left(C_{1}\right)}{\operatorname{Total}\left(C_{1}\right)} \times \frac{\operatorname{Obs}\left(C_{2}\right)}{\operatorname{Total}\left(C_{2}\right)} \times \text { Total }
\end{aligned}
$$

Significance is calculated via Fisher's exact test over $2 \times 2$ contingency tables for consonants in first position versus consonants in second position. Fisher's exact test is chosen over chi-squared as it is more reliable with smaller amounts of data (Agresti 2007: 45). As each row in Table 1 is a different statistical test of a collapsed version of the full $5 \times 5$ contingency table (Table 3 ), the Bonferroni correction for 8 tests is applied to an alpha of 0.05 , resulting in $0.00625(0.05 / 8$, Sharpe 2015$) .{ }^{5}$ If $p$ is below this level and $\mathrm{O} / \mathrm{E}<1$, I assume a categorical ban in the analysis. ${ }^{6}$ If $p<0.00625$ and $\mathrm{O} / \mathrm{E}>1$, I use this as evidence for the mappings of certain inputs (see 21).

3.2 Results The full results for all stops sorted by place are given in Tables 3-5.

Table 3: Observed values for all Ngbaka oral and nasal stops by place

\begin{tabular}{rcccccc}
\hline & cor & dor & lab & lab-dor & other & Mar C1 \\
\hline cor & 28 & 34 & 17 & 11 & 70 & 160 \\
dor & 43 & 26 & 27 & 1 & 105 & 202 \\
lab & 33 & 31 & 12 & 0 & 76 & 152 \\
lab-dor & 15 & 13 & 2 & 11 & 45 & 86 \\
other & 37 & 67 & 35 & 14 & 127 & 280 \\
\hline Mar C2 & 156 & 171 & 93 & 37 & 423 & 880 \\
\hline
\end{tabular}

Table 4: Expected values for all Ngbaka oral and nasal stops by place

\begin{tabular}{rcccccc}
\hline & cor & dor & lab & lab-dor & other & Mar C1 \\
\hline cor & 28.36 & 31.09 & 16.91 & 6.73 & 76.91 & 160 \\
dor & 35.81 & 39.25 & 21.35 & 8.49 & 97.10 & 202 \\
lab & 26.95 & 29.54 & 16.06 & 6.39 & 73.06 & 152 \\
lab-dor & 15.25 & 16.71 & 9.09 & 3.62 & 41.34 & 86 \\
other & 49.64 & 54.41 & 29.59 & 11.77 & 134.59 & 280 \\
\hline Mar C2 & 156 & 171 & 93 & 37 & 423 & 880 \\
\hline
\end{tabular}

Labial and coronal homorganic pairs occur as expected. Labial-dorsal homorganic pairs are significantly overrepresented. Homorganic dorsal pairs are also likely significantly underrepresented. However, unlike with the underrepresented semihomorganic pairs, the actual number of observed dorsal pairs is relatively high due to the high frequency of dorsals in general-there are 26 dorsal pairs of an expected 39.25. In all other cases of statistical underrepresentation, I assume a categorical grammatical ban on those segments. For

5 Thanks to Adam Chong for assistance with this section.

6 Except for dorsal pairs; see the discussion in the next section. 
dorsals, however, the theoretical analysis treats them as grammatically licit and I leave this problem for future work. If homorganic dorsal pairs are indeed underrepresented but not banned outright, a gradient acceptability analysis similar to Coetzee \& Pater 2008 might be appropriate.

Table 5: O/E ratios for all Ngbaka oral and nasal stops by place.

\begin{tabular}{rccccc}
\hline & cor & dor & lab & lab-dor & other \\
\hline cor & $\mathbf{0 . 9 9}$ & 1.09 & 1.01 & 1.64 & 0.91 \\
dor & 1.20 & $\mathbf{0 . 6 6}\left(^{*}\right)$ & 1.26 & $\mathbf{0 . 1 2} *$ & 1.08 \\
lab & 1.22 & 1.05 & $\mathbf{0 . 7 5}$ & $\mathbf{0 . 0 0} *$ & 1.04 \\
lab-dor & 0.98 & $\mathbf{0 . 7 8}$ & $\mathbf{0 . 2 2} *$ & $\mathbf{3 . 0 4} *$ & 1.09 \\
other & 0.75 & 1.23 & 1.18 & 1.19 & 0.94 \\
\hline
\end{tabular}

Starred cells indicate significance. Italic cells are untested for significance.

See Appendix A for information on accessing the full wordlist and calculations. For a complete discussion of the dictionary analysis, see Danis (in progress).

\section{Analysis}

4.1 Representation The analysis here models Place Agreement on Labials (PAL), Place Agreement on Dorsals (PAD), and Voicing Agreement (VA). The relevant features are [voice] and the major place features. Segments differ in both their voicing value and the following place combinations:

(8) Segmental representations

\begin{tabular}{|c|c|c|}
\hline & place & [voice] \\
\hline $\mathrm{t} / \mathrm{d}$ & [cor] & $-/+$ \\
$\mathrm{p} / \mathrm{b}$ & {$[\mathrm{lab}]$} & $-/+$ \\
$\mathrm{k} / \mathrm{g}$ & {$[\mathrm{dor}]$} & $-/+$ \\
$\mathrm{kp} / \mathrm{gb}$ & {$[\mathrm{lab}],[$ dor] } & $-/+$ \\
\hline
\end{tabular}

There is no structural distinction between the two place features of the labial-dorsal segment. Doublyarticulated stops in general have two places of equal phonetic stricture (see Ladefoged 1968, Connell 1994, Ladefoged \& Maddieson 1996 among others). Theories that differentiate the place features of doublyarticulated segments like labial-dorsals distinguish abstract primary place, where one place is marked as primary even though they have equal stricture. The pointer device of Sagey 1986 is one such implementation, as is government (van de Weijer 1996) or utilizing C- and V-place distinctions (Cahill 1999). However, abstract primary place is not necessary. This not only simplifies the representation and therefore the candidate space, but also uses independent mechanisms (constraint ranking) to replace the work of specific devices meant to model abstract primary place.

Labial-dorsals are the only complex segment considered in this analysis. The matter of what other place combinations that are possible is left aside. Other place combinations, if phonologically licit (cf. Bennett 2014), would be ruled out through some independent ranking or grammatical mechanism (see for instance Danis 2017).

All inputs and candidates are indicated via pairs of segments. Surface correspondence is indicated via subscripted indices. Candidates are given as $\mathrm{CaCa}$ forms:

a. No surface correspondence:
$\left[\mathrm{t}_{1} a \mathrm{p}_{2} \mathrm{a}\right]$

b. Surface correspondence:

$\left[\widehat{\mathrm{kp}}_{1} \mathrm{akp}\right.$ a $]$

4.2 Constraints To model the place and voicing restrictions in $\mathrm{ABC}$, there are four general types of constraints: CC Ident, IO Ident (abbreviated id-cc and id-io, respectively), Corr, and markedness. Following Bennett 2013, Corr constraints are defined over individual features. Rose \& Walker 2004: (20) use constraints defined over a similarity scale; however, this scale makes reference to homorganic and heterorganic pairs, which is problematic for semihomorganic pairs. Crucially for the Ngbaka patterns, there is one Corr constraint for each place feature, defined as follows: 


\section{(10) Corr.[dorsal]}

Assign a violation if:

[dorsal] $\in \mathrm{S}_{1}, \mathrm{~S}_{2}$ and

$\mathrm{S}_{1}$ and $\mathrm{S}_{2}$ are output segments not in correspondence

In addition to the above, Corr.[labial] and Corr.[dorsal] are also defined. There is one ad hoc constraint to capture the asymmetry of PAD:

\section{(11) Corr.[dor]/C2=[lab]}

Assign a violation if:

[dorsal] $\in \mathrm{S}_{1}, \mathrm{~S}_{2}$ and

$\mathrm{S}_{1}$ and $\mathrm{S}_{2}$ are output segments not in correspondence and

[labial] $\in \mathrm{S}_{2}$

This constraint demands correspondence from pairs that are both dorsal, and where the second consonant is labial. $^{7}$

\begin{tabular}{|l||c|c|l|}
\hline output & Corr.[dorsal] & Corr.[dor]/C2=[lab] & Comment \\
\hline \hline $\mathrm{k}_{1} \mathrm{ak}_{2} \mathrm{a}$ & 1 & 0 & $\mathrm{C} 2$ is not labial \\
\hline $\mathrm{kp}_{1} \mathrm{ak}_{2} \mathrm{a}$ & 1 & 0 & $\mathrm{C} 2$ is not labial \\
\hline $\mathrm{k}_{1} \mathrm{akp}_{2} \mathrm{a}$ & 1 & 1 & $\mathrm{C} 2$ is labial \\
\hline $\mathrm{kp}_{1} \mathrm{akp}_{2} \mathrm{a}$ & 1 & 1 & $\mathrm{C} 2$ is labial \\
\hline $\mathrm{k}_{1} \mathrm{akp}_{1} \mathrm{a}$ & 0 & 0 & $\mathrm{C} 1$ and $\mathrm{C} 2$ are in correspondence \\
\hline
\end{tabular}

Identity, for both segments in input/output (io) correspondence, or surface (cc) correspondence, is evaluated via the following constraints. There is a single id-cc.place constraint for surface correspondence identity:

\section{(13) id-cc.place}

If $\mathrm{S}_{1}$ and $\mathrm{S}_{2}$ are segments in cc correspondence,

Assign 1 violation if [dorsal] $\in \mathrm{S}_{1} \neq[$ dorsal $] \in \mathrm{S}_{2}$ and

Assign 1 violation if [labial] $\in \mathrm{S}_{1} \neq[$ [labial $] \in \mathrm{S}_{2}$ and

Assign 1 violation if [coronal] $\in \mathrm{S}_{1} \neq\left[\right.$ coronal] $\in \mathrm{S}_{2}$

Identity between consonants in surface correspondence evaluates every disparity between the set of major place features.

(14) Where $S_{1}$ and $S_{2}$ are potential segments in correspondence:

\begin{tabular}{|c|c||c|l|}
\hline $\mathrm{S}_{1}$ & $\mathrm{~S}_{2}$ & id-cc.place & Comment \\
\hline \hline $\mathrm{k}$ & $\mathrm{kp}$ & 1 & [labial] disparity \\
\hline $\mathrm{k}$ & $\mathrm{p}$ & 2 & [labial] and [dorsal] disparity \\
\hline $\mathrm{t}$ & $\mathrm{kp}$ & 3 & [labial], [coronal], and [dorsal] disparity \\
\hline
\end{tabular}

Identity is defined for privative features following Pater 1999, while treating place features together as a class. Also following Pater 1999, two constraints are used to mediate independently the addition and the removal of place features between input and output.

(15) $\mathbf{i d}\langle\mathbf{i}, \mathbf{o}\rangle$.place

If $\mathrm{S}_{\mathrm{i}}$ and $\mathrm{S}_{\mathrm{o}}$ are segments in io correspondence,

Assign 1 violation if [dorsal] $\in \mathrm{S}_{\mathrm{i}}$ and [dorsal] $\notin \mathrm{S}_{\mathrm{o}}$ and

Assign 1 violation if [labial] $\in \mathrm{S}_{\mathrm{i}}$ and [labial] $\notin \mathrm{S}_{\mathrm{o}}$ and

Assign 1 violation if [coronal] $\in \mathrm{S}_{\mathrm{i}}$ and [coronal] $\notin \mathrm{S}_{\mathrm{o}}$

7 This could be related to the cross-linguistic generalization that labial-dorsals are dispreferred word-internally. For instance, Cahill 2000 defines a constraint KP-mi that penalizes labial-dorsals that appear morpheme-internally. The constraint Corr.[dor]/C2=[lab] could alternatively be defined as a local constraint conjunction between this constraint and Corr.[dorsal]: [Corr.[dorsal]\&KP-mi]. This resulting constraint would have the same violation profile as Corr.[dor] $/ \mathrm{C} 2=[\mathrm{lab}]$ does in (12). 
(16) $\mathbf{i d}\langle\mathbf{o}, \mathbf{i}\rangle \cdot$ place

If $\mathrm{S}_{\mathrm{i}}$ and $\mathrm{S}_{\mathrm{o}}$ are segments in io correspondence, Assign 1 violation if [dorsal] $\notin \mathrm{S}_{\mathrm{i}}$ and [dorsal] $\in \mathrm{S}_{\mathrm{o}}$ and Assign 1 violation if [labial] $\notin \mathrm{S}_{\mathrm{i}}$ and [labial] $\in \mathrm{S}_{\mathrm{o}}$ and Assign 1 violation if [coronal] $\notin \mathrm{S}_{\mathrm{i}}$ and [coronal] $\in \mathrm{S}_{\mathrm{o}}$

The above two constraints evaluate place disparities in a parallel fashion to id-cc.place. The only differences are that they operate on io correspondence, and are directional. It should be stressed that place faithfulness is not strict equivalence: once segments with complex place are part of the system, there are different levels of disparities that are possible between two segments in correspondence (as illustrated in (13)). For detailed arguments on why place faithfulness must have this articulated level of evaluation, see Danis 2014, 2017. These constraints essentially treat the notion of place features as a class, and are evaluated similarly to the definitions based on set theory in Feature Class Theory (Padgett 1995, 2002).

In addition to place identity, there are standard Ident constraints (following McCarthy \& Prince 1995) for the feature [voice] as well:

(17) id-cc.[voice] / id-io.[voice]

If $\mathrm{S}_{1}$ and $\mathrm{S}_{2}$ are segments in cc/io correspondence,

Assign 1 violation if $S_{1}$ is [ $\alpha$ voice] and $S_{2}$ is [ $-\alpha$ voice]

Again, (17) defines both the input/output and surface correspondence constraints. While it might be necessary to have directional io [voice] identity as well (see e.g. Rose \& Walker 2004: (24)), a single constraint is used here for simplicity and to focus on the place interactions.

4.3 Ranking The full Ngbaka ranking is shown in Figure $1 .^{8}$ All ranking information is shown in Comparative Tableaux (CTs), following Prince 2002. Each row of a CT contains an Elementary Ranking Condition (ERC), where a constraint preferring the winning candidate (W) must dominate all constraints preferring the losing candidate (L). ${ }^{9}$
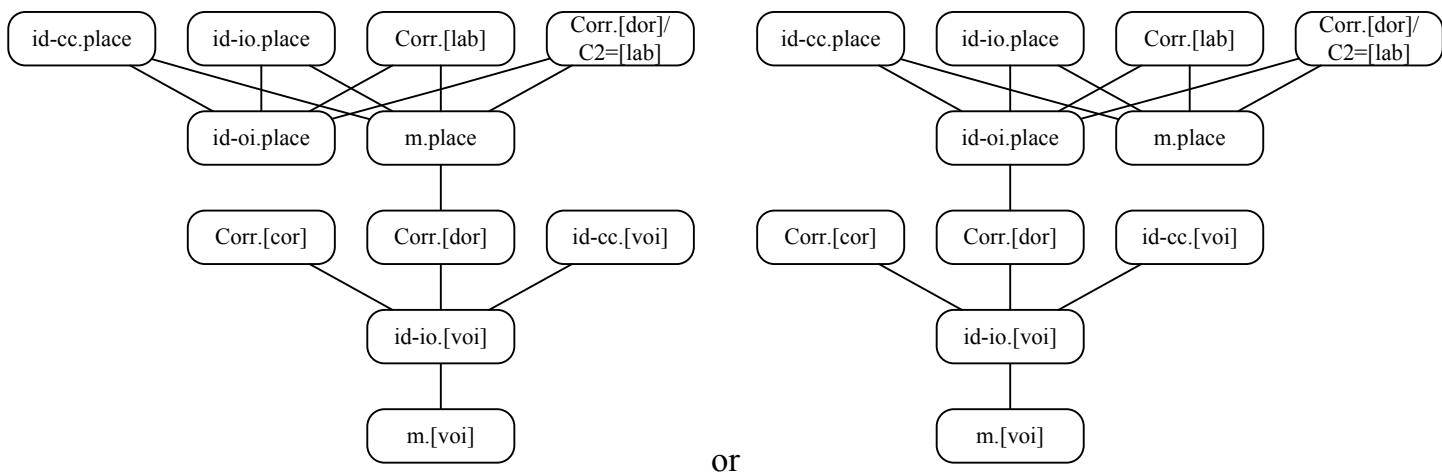

Figure 1: Full Ngbaka ranking (disjunctive)

\footnotetext{
8 All ranking calculations done in OT Workplace (Prince, Tesar \& Merchant 2016). Candidates were generated via a Python script and and all constraint evaluation was automated via VBA.

9 In some of the following CTs, constraints that do not differentiate between any of the winner/loser pairs are not shown for space considerations; however, no ranking information is lost as the full tableau is recoverable as the complete list of constraints is shown in (18).
} 
(18) Full support for Ngbaka

\begin{tabular}{|c|c|c|c|c|c|c|c|c|c|c|c|c|c|c|}
\hline & Input & Winner & Loser & 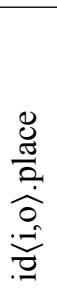 & 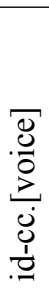 & 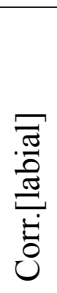 & $\begin{array}{l}\bar{\Xi} \\
0 \\
0 \\
0 \\
\dot{0} \\
\dot{0} \\
0\end{array}$ & 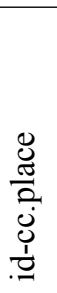 & 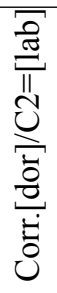 & $\begin{array}{l}\frac{\mathscr{J}}{0} \\
\frac{\pi}{0} \\
\text {. }\end{array}$ & 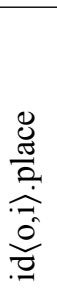 & $\begin{array}{l}\bar{\Xi} \\
\overline{0} \\
\overline{0} \\
\dot{0} \\
\dot{0}\end{array}$ & 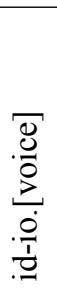 & $\begin{array}{l}0.0 \\
\stackrel{0}{0} \\
\dot{g} \\
\dot{g}\end{array}$ \\
\hline$\overline{\text { a. }}$ & $\overline{\mathrm{k}-\mathrm{kp}}$ & $\overline{\mathrm{kp}_{1} \mathrm{akp}_{1} \mathrm{a}}$ & $\begin{array}{l}k_{1} a p_{2} a \\
k_{1} a_{1} a\end{array}$ & $\overline{\mathrm{W}}$ & & & & & & 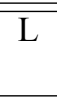 & 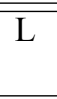 & & & \\
\hline & k-g & $\mathrm{k}_{1} \mathrm{ak}_{1} \mathrm{a}$ & $\mathrm{k}_{1} \mathrm{ag}_{1} \mathrm{a}$ & & $\mathrm{W}$ & & & & & & & & $\mathrm{L}$ & $\mathrm{W}$ \\
\hline c. & $\mathrm{p}-\mathrm{kp}$ & $\overline{\mathrm{kp}}_{1} \mathrm{a} \mathrm{kp}_{1} \mathrm{a}$ & $\mathrm{p}_{1} \mathrm{akp}{ }_{2} \mathrm{a}$ & & & $\mathrm{W}$ & & & & $\mathrm{L}$ & $\mathrm{L}$ & & & \\
\hline d. & $\mathrm{t}-\mathrm{d}$ & $\mathrm{t}_{1} \mathrm{at}_{1} \mathrm{a}$ & $\mathrm{t}_{1} \mathrm{ad}_{2} \mathrm{a}$ & & & & $\mathrm{W}$ & & & & & & $\mathrm{L}$ & $\mathrm{W}$ \\
\hline e. & $\mathrm{k}-\widehat{\mathrm{kp}}$ & $\widehat{\mathrm{kp}}_{1} \mathrm{akp}{ }_{1} \mathrm{a}$ & $\mathrm{k}_{1} \mathrm{akp}{ }_{1} \mathrm{a}$ & & & & & $\mathrm{W}$ & & $\mathrm{L}$ & $\mathrm{L}$ & & & \\
\hline f. & $\mathrm{k}-\mathrm{kp}$ & $\widehat{\mathrm{kp}}_{1} \mathrm{akp}{ }_{1} \mathrm{a}$ & $\mathrm{k}_{1} \mathrm{akp}_{2} \mathrm{a}$ & & & & & & W & $\mathrm{L}$ & $\mathrm{L}$ & $\mathrm{W}$ & & \\
\hline g. & $\widehat{\mathrm{kp}}-\mathrm{k}$ & $\mathrm{kp}_{1} \mathrm{ak}_{2} \mathrm{a}$ & $\mathrm{kp}_{1} \mathrm{akp}_{1} \mathrm{a}$ & & & & & & & $\mathrm{W}$ & $\mathrm{W}$ & $\mathrm{L}$ & & \\
\hline h. & $\mathrm{k}-\mathrm{g}$ & $\mathrm{k}_{1} \mathrm{ak}_{1} \mathrm{a}$ & $\mathrm{k}_{1} \mathrm{ag}_{2} \mathrm{a}$ & & & & & & & & & $\mathrm{W}$ & $\mathrm{L}$ & $\mathrm{W}$ \\
\hline i. & $\mathrm{k}-\mathrm{b}$ & $\mathrm{k}_{1} \mathrm{ab}_{2} \mathrm{a}$ & $\mathrm{k}_{1} \mathrm{ap}_{2} \mathrm{a}$ & & & & & & & & & & $\mathrm{W}$ & $\mathrm{L}$ \\
\hline
\end{tabular}

Detailed rankings for each process are discussed in the following sections. Note that there is one irreducible disjunction in the full ranking: ERC $18 \mathrm{~g}$. For $/ \mathrm{kp}-\mathrm{k} /$ to surface faithfully and not be in correspondence, it must be preferred to $\left[\mathrm{kp}_{1} a \widehat{\mathrm{kp}}_{1} \mathrm{a}\right]$, which is unfaithful but in correspondence. The winner is better both in terms of markedness (m.place) and in not adding place features to the output (id $\langle 0, i\rangle$.place), so one of these constraints must dominate Corr.[dorsal]. This disjunction is represented by the two Hasse diagrams in Figure 1.

4.3.1 Place Agreement on Labials The ranking necessary for Place Agreement on Labials is shown below.

(19) CT for $/ \mathrm{kp}-\mathrm{p} /$

\begin{tabular}{|c|c|c|c|c|c|c|c|c|}
\hline & Input & Winner & Loser & 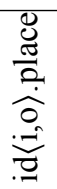 & 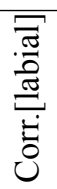 & 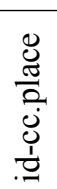 & $\begin{array}{l}\stackrel{\Xi}{\Xi} \\
\frac{\tilde{g}}{0} \\
\dot{\Xi}\end{array}$ & 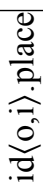 \\
\hline a. & $\widehat{\mathrm{kp}}-\mathrm{p}$ & $\overline{\mathrm{kp}}_{1} \mathrm{akp}{ }_{1} \mathrm{a}$ & $\begin{array}{l}\mathrm{k}_{1} \mathrm{ap}_{2} \mathrm{a} \\
\mathrm{p}_{1} \mathrm{ap}_{1} \mathrm{a}\end{array}$ & $\overline{\mathrm{WW}}$ & & & $\overline{\mathrm{L}}$ & 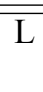 \\
\hline b. & $\widehat{\mathrm{kp}}-\mathrm{p}$ & $\mathrm{kp}_{1} \mathrm{akp}_{1} \mathrm{a}$ & $\mathrm{kp}_{1} \mathrm{ap}_{2} \mathrm{a}$ & & $\mathrm{W}$ & & $\mathrm{L}$ & $\mathrm{L}$ \\
\hline c. & $\mathrm{kp}-\mathrm{p}$ & $\mathrm{kp}_{1} \mathrm{akp}_{1} \mathrm{a}$ & $\mathrm{kp}_{1} \mathrm{ap}_{1} \mathrm{a}$ & & & W & $\mathrm{L}$ & $\mathrm{L}$ \\
\hline
\end{tabular}

Following the basic ABC schema for long-distance interaction, ERC 19b demands Corr.[labial] dominate both place markedness m.place and faithfulness id $\langle\mathrm{o}, \mathrm{i}\rangle$.place, as this constraint prefers the winner where the consonants are in correspondence. All labial pairs, including those with labial-dorsals, correspond. In ERC $19 \mathrm{c}$, id-cc.place must dominate both m.place and id $\langle\mathrm{o}, \mathrm{i}\rangle$.place as well, as identity of surface segments is more important than removing place features from the input (id $\langle\mathrm{o}, \mathrm{i}\rangle$.place) or being more marked (m.place).

PAL in Ngbaka is a static restriction, so there are no active alternations to show what the actual mappings are. The winning candidate is assumed to be $\left[\widehat{\mathrm{kp}}_{1} \mathrm{akp}, \mathrm{a}\right]$, where [dorsal] place is added to the output to satisfy id-cc.place. ${ }^{10}$ This candidate is possible because it satisfies id $\langle i, o\rangle$.place through not removing any place features, although it does add one (violating id $\langle\mathrm{o}, \mathrm{i}\rangle$.place) and is more marked than the faithful candidate. This is expressed in ERC 19a, where the losing candidate is actually a tie between the dissimilation candidate $\left[\mathrm{k}_{1} a \mathrm{p}_{2} \mathrm{a}\right]$ and the simple agreement candidate $\left[\mathrm{p}_{1} a \mathrm{p}_{1} \mathrm{a}\right]$, where surface identity is satisfied through removing a place feature. The choice of possible agreement and dissimilation optima are summarized in the following table:

${ }^{10}$ Note that this differs from the presented version, where there was only a single io place faithfulness constraint and the tied losers in $19 \mathrm{a}$ were assumed to be the co-optima. 
(20)

\begin{tabular}{|lr||c|c|c||l|l|}
\hline & $/ \mathrm{kpapa} /$ & $\mathrm{id}\langle\mathrm{i}, \mathrm{o}\rangle$. place & m.place & $\mathrm{id}\langle\mathrm{o}, \mathrm{i}\rangle$.place & Disparity & Process \\
\hline \hline $\mathrm{a}$. & $\mathrm{k}_{1} \mathrm{ap} \mathrm{p}_{2} \mathrm{a}$ & 1 & 2 & 0 & {$[$ labial $] \rightarrow \varnothing$} & Dissimilation \\
\hline b. & $\mathrm{p}_{1} \mathrm{ap}_{1} \mathrm{a}$ & 1 & 2 & 0 & {$[$ dorsal $] \rightarrow \varnothing$} & Simple agreement \\
\hline c. & $\mathrm{kp}_{1} \mathrm{akp}_{1} \mathrm{a}$ & 0 & 4 & 1 & $\varnothing \rightarrow[$ dorsal $]$ & Complex agreement \\
\hline
\end{tabular}

The input mapping to any of these choices is still a kind of major place long-distance interaction, whether it's dissimilation (a) or agreement (b or c). As Bennett 2013 demonstrated, most static long-distance interactions have either an agreement or dissimilation analysis, both caused by the same basic $\mathrm{ABC}$ ranking schema where correspondence is demanded of feature $\mathrm{F}$ and agreement demanded for feature $\mathrm{G}$. Faithfulness rankings for $\mathrm{F}$ and $\mathrm{G}$ determine whether it is agreement or dissimilation. It should be noted here that features $F$ and $G$, which are both major place features, are controlled by the same faithfulness constraints. The dissimilation candidate in (a) and the simple agreement candidate in (b) can only be differentiated by a more articulated theory of markedness.

There are, however, three reasons why $\left[\widehat{\mathrm{kp}}_{1} \mathrm{akp}{ }_{1} \mathrm{a}\right]$ is assumed to be the optimum:

a. $\widehat{\mathrm{KP}} \ldots \widehat{\mathrm{KP}}$ pairs are significantly overrepresented in the dictionary data.

b. Agreement processes cross-lingusitically agree for the more marked feature value.

c. Rose \& Walker 2004 cite experimental evidence that the addition of a place of articulation is preferred to the removal of one.

As shown in Table $1, \widehat{\mathrm{KP}} \ldots \widehat{\mathrm{KP}}$ pairs are significantly overrepresented on the surface. This suggests that inputs other than $/ \overparen{\mathrm{KP}} \ldots \widehat{\mathrm{KP}} /$ are mapping to $[\widehat{\mathrm{KP}} \ldots \widehat{\mathrm{KP}}]$, such as the relevant semihomorganic pairs shown below. ${ }^{11}$

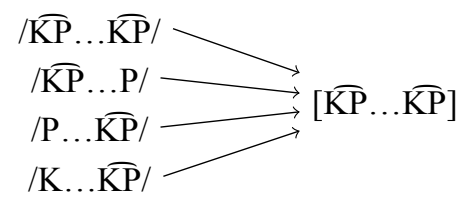

Additionally, Iacoponi 2016 discusses a cross-linguistic generalization where "in dominent-recessive consonant harmony, the target is always the marked feature". In the cases surveyed there, voicing assimilation always maps to [+voice], nasal assimilation to [+nasal], and dorsal assimilation to [+high], with several other cases as well. Since the presence of a place feature is usually assumed to be more marked than the absence of one (either due to place being privative or in explicit theories of place markedness theories in OT), agreement to complex place would fit in with the generalization in Iacoponi 2016.

Lastly, Rose \& Walker cite Pouplier et al. 1999 as evidence that "[t]here is no coarticulation impetus for place gestures to be reduced, and accordingly, it appears that retention of place features is favored." (Rose \& Walker 2004: 519). They go on to state: "We suggest that the additive property of speech errors with place is mirrored in consonantal agreement in the respect that place articulations can be added but not removed. Place agreement is avoided, because complex stops are generally dispreferred." (Rose \& Walker 2004: 520). Ngbaka, then, is a case where complex segments are allowed and place agreement is detectible. It is important to note that even if Ngbaka does not contain long-distance place agreement, but rather dissimilation, these patterns are still caused by an active id-cc.place dominating some io place faithfulness.

4.3.2 Place Agreement on Dorsals Place Agreement on Dorsals (PAD) is the only directional process found in the Ngbaka data. It only applies to forms with an initial dorsal and a medial labial-dorsal: K... $\widehat{\mathrm{KP}}$.

\footnotetext{
${ }^{11}$ Thanks to Luca Iacoponi and Sharon Rose for discussion on this point.
} 
(23)

$\mathrm{CT}$ for $/ \mathrm{k}-\mathrm{kp} /$

\begin{tabular}{|c|c|c|c|c|c|c|c|c|c|}
\hline & Input & Winner & Loser & 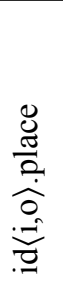 & 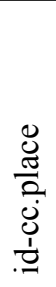 & 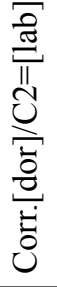 & 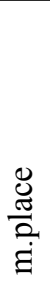 & 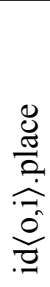 & $\begin{array}{l}\bar{\sigma} \\
\overline{0} \\
\overline{0} \\
\dot{0} \\
\dot{0}\end{array}$ \\
\hline & $\mathrm{k}-\widehat{\mathrm{kp}}$ & $\widehat{\mathrm{kp}}_{1} \mathrm{akp}{ }_{1} \mathrm{a}$ & $\begin{array}{l}k_{1} a p_{2} a \\
k_{1} a_{1} a\end{array}$ & $\mathrm{~W}$ & & & $\mathrm{~L}$ & $\mathrm{~L}$ & \\
\hline & $\mathrm{k}-\widehat{\mathrm{kp}}$ & $\widehat{\mathrm{kp}}_{1} \mathrm{akp}{ }_{1} \mathrm{a}$ & $\mathrm{k}_{1} \mathrm{akp}_{1} \mathrm{a}$ & & W & & $\mathrm{L}$ & $\mathrm{L}$ & \\
\hline c. & $\mathrm{k}-\mathrm{kp}$ & $\mathrm{kp}_{1} \mathrm{akp}_{1} \mathrm{a}$ & $\mathrm{k}_{1} \mathrm{akp}{ }_{2} \mathrm{a}$ & & & W & $\mathrm{L}$ & $\mathrm{L}$ & W \\
\hline
\end{tabular}

Again, the winning candidate is assumed to be $\left[\mathrm{kp}_{1} \mathrm{akp}\right.$ a $\mathrm{a}$, following the reasons in (21). To capture this asymmetry, the constraint Corr.[dor]/C2=[lab] demands correspondence from forms where both consonants are [dorsal] but the second is also [labial]. While both Corr.[dor]/C2=[lab] and Corr.[dorsal] prefer the winning candidate in ERC 23c, the next tableau shows that Corr.[dorsal] cannot dominate both m.place and id $\langle\mathrm{o}, \mathrm{i}\rangle$.place:

(24) $\mathrm{CT}$ for $/ \mathrm{kp}-\mathrm{k} /$

\begin{tabular}{|c|c|c|c|c|c|c|c|c|c|}
\hline & Input & Winner & Loser & 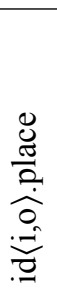 & 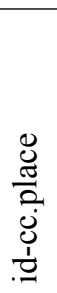 & 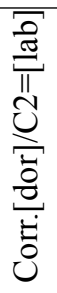 & $\begin{array}{l}\frac{\mathscr{U}}{\tilde{g}} \\
\stackrel{0}{\mathrm{~g}} \\
\end{array}$ & 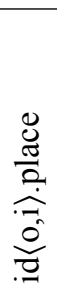 & 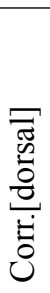 \\
\hline$\overline{\mathrm{a} .}$ & $\widehat{\mathrm{kp}}-\mathrm{k}$ & $\overline{\mathrm{kp}_{1} \mathrm{ak}_{2} \mathrm{a}}$ & $\begin{array}{l}\mathrm{k}_{1} \mathrm{ak}_{1} \mathrm{a} \\
\mathrm{p}_{1} \mathrm{ak}_{2} \mathrm{a}\end{array}$ & $\overline{\mathrm{W}}$ & & & $\overline{\mathrm{L}}$ & & $\overline{\mathrm{L}}$ \\
\hline b. & $\widehat{\mathrm{kp}}-\mathrm{k}$ & $\mathrm{kp}_{1} \mathrm{ak}_{2} \mathrm{a}$ & $\mathrm{kp}_{1} \mathrm{ak}_{1} \mathrm{a}$ & & $\mathrm{W}$ & & & & $\mathrm{L}$ \\
\hline c. & $\widehat{\mathrm{kp}}-\mathrm{k}$ & $\mathrm{kp}_{1} \mathrm{ak}_{2} \mathrm{a}$ & $\widehat{\mathrm{kp}}_{1} \mathrm{akp}{ }_{1} \mathrm{a}$ & & & & $\mathrm{W}$ & $\mathrm{W}$ & $\mathrm{L}$ \\
\hline
\end{tabular}

In order for $/ \mathrm{kp}-\mathrm{k} /$ to surface faithfully, it must not be in correspondence. If it were, it would be subject to PAD. The optimum is indeed not in correspondence: $\left[\widehat{\mathrm{kp}}_{1} \mathrm{ak}_{2} \mathrm{a}\right]$. The constraint Corr.[dor]/C2=[lab] does not differentiate between any of the candidates in this candidate set, as none of them are of the form $\mathrm{K}$... $\widehat{\mathrm{KP}}$.

Treating the directionality of PAD as a restriction in correspondence, not on the direction of place agreement, makes the explicit prediction that $\widehat{\mathrm{KP}} \ldots \mathrm{K}$ forms are not subject to other types of agreement as well, such as Voicing Agreement. This prediction is borne out:

a. gbaka 'help, rescue'

(Maes 1959: 77)

b. gbákj- 'tree branch'

(Maes 1959: 77)

If the optimum to $/ \mathrm{kp}-\mathrm{k} /$ in (24) were in correspondence, then we should expect VA to apply as well. However, this is not the case. Dorsal semihomorganic forms that disagree in voicing, such as those in (25), surface faithfully both in terms of place and voice.

(26) CT for $/ \mathrm{gb}-\mathrm{k} /$

\begin{tabular}{|c|c|c|c|c|c|c|c|c|c|c|c|}
\hline & Input & Winner & Loser & $\begin{array}{l}\bar{g} \\
.0 \\
0 \\
0 \\
0 \\
.0 \\
.0\end{array}$ & 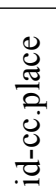 & 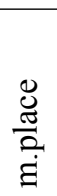 & 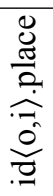 & $\begin{array}{l}\overline{\overline{0}} \\
\dot{0} \\
\overline{0} \\
\dot{0} \\
\dot{0}\end{array}$ & 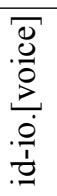 & $\begin{array}{l}\stackrel{.}{.0} \\
\stackrel{0}{0} \\
\dot{g}\end{array}$ & Loser Comment \\
\hline a. & $\overline{\mathrm{gb}}-\mathrm{k}$ & $\overline{\mathrm{gb}_{1} \mathrm{ak}_{2} \mathrm{a}}$ & $\overline{\mathrm{gb}_{1} \mathrm{ak}_{1} \mathrm{a}}$ & $\overline{\mathrm{W}}$ & $\overline{\mathrm{W}}$ & & & $\overline{\mathrm{L}}$ & & & Faithful, in corr. \\
\hline b. & gb-k & $\mathrm{gb}_{1} \mathrm{ak}_{2} \mathrm{a}$ & $\mathrm{gb}_{1} \mathrm{akp}_{1} \mathrm{a}$ & $\mathrm{W}$ & & $\mathrm{W}$ & $\mathrm{W}$ & $\mathrm{L}$ & & & Place agreement \\
\hline c. & gb-k & $\mathrm{gb}_{1} \mathrm{ak}_{2} \mathrm{a}$ & $\mathrm{kp}_{1} \mathrm{ak}_{1} \mathrm{a}$ & & $\mathrm{W}$ & & & $\mathrm{L}$ & $\mathrm{W}$ & $\mathrm{L}$ & Voicing agreement \\
\hline d. & $\overline{\mathrm{gb}}-\mathrm{k}$ & $\mathrm{gb}_{1} \mathrm{ak}_{2} \mathrm{a}$ & $\mathrm{kp}_{1} \mathrm{akp} \hat{\mathrm{kp}}_{1} \mathrm{a}$ & & & $\mathrm{W}$ & $\mathrm{W}$ & $\mathrm{L}$ & $\mathrm{W}$ & $\mathrm{L}$ & Place \& voicing agreement \\
\hline
\end{tabular}


In ERC 26a, the loser is faithful and in correspondence, and therefore violates both id-cc.[voice] and idcc.place. Both id-cc constraints prefer the winner as it trivially satisfies surface correspondence identity through lack of correspondence.

Failure of VA to apply here is the reason why the absence of place agreement on $\widehat{\mathrm{KP}}$...K forms must be due to non-correspondence. If place agreement were directional, either with directional versions of id-cc.place or through positional faithfulness, then $[\widehat{\mathrm{KP}} \ldots \mathrm{K}]$ would be in correspondence, but agreement would not happen in this direction. However, once in correspondence, those forms are susceptible to other agreement, as there is a single correspondence relationship that holds between segments. Because these forms are not subject to voicing agreement, the lack of place agreement must be due to lack of correspondence.

4.3.3 Voicing Agreement Voicing Agreement holds between homorganic consonants, and demands that they agree in voicing.

\section{CT for Voicing Agreement}

\begin{tabular}{|c|c|c|c|c|c|c|c|c|c|c|c|}
\hline & Input & Winner & Loser & 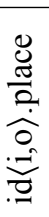 & 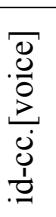 & 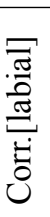 & 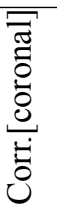 & 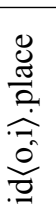 & $\begin{array}{l}\bar{\sigma} \\
\overline{0} \\
\overline{0} \\
\dot{0} \\
\dot{0}\end{array}$ & 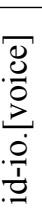 & $\begin{array}{l}\stackrel{0}{0} \\
\stackrel{0}{8} \\
\dot{g}\end{array}$ \\
\hline a. & k-g & $\mathrm{k}_{1} \mathrm{ak}_{1} \mathrm{a}$ & $\mathrm{k}_{1} \mathrm{ab}_{2} \mathrm{a}$ & $\overline{\mathrm{W}}$ & & & & W & & $\mathrm{L}$ & $\overline{\mathrm{W}}$ \\
\hline & k-g & $\mathrm{k}_{1} \mathrm{ak}_{1} \mathrm{a}$ & $\mathrm{k}_{1} \mathrm{ag}_{1} \mathrm{a}$ & & $\mathrm{W}$ & & & & & $\mathrm{L}$ & $\mathrm{W}$ \\
\hline c. & $\mathrm{p}-\mathrm{b}$ & $\mathrm{p}_{1} \mathrm{ap}_{1} \mathrm{a}$ & $\mathrm{p}_{1} \mathrm{ab}_{2} \mathrm{a}$ & & & $\mathrm{W}$ & & & & $\mathrm{L}$ & $\mathrm{W}$ \\
\hline d. & $t-d$ & $\mathrm{t}_{1} \mathrm{at}_{1} \mathrm{a}$ & $\mathrm{t}_{1} \mathrm{ad}_{2} \mathrm{a}$ & & & & W & & & $\mathrm{L}$ & $\mathrm{W}$ \\
\hline e. & k-g & $\mathrm{k}_{1} \mathrm{ak}_{1} \mathrm{a}$ & $\mathrm{k}_{1} \mathrm{ag}_{2} \mathrm{a}$ & & & & & & W & $\mathrm{L}$ & W \\
\hline
\end{tabular}

VA applies to all homorganic pairs - all of Corr.[dorsal], Corr.[coronal], and Corr.[labial] dominate idio.[voice] as does id-cc.[voice] (ERCs 27c-e). Faithful voicing violates id-cc.[voice] (ERC 27b), and the place dissimilation candidate loses to the voicing agreement candidate (ERC 27a). Note that even though Corr.[labial] dominates Corr.[dorsal] because of PAD, both constraints still dominate the relevant constraints for VA. While all the ERCs in (27) are disjunctive, id-io.[voice] must dominate m.voice, as ERC 18i shows.

4.4 Summary The analysis here accounts for Place Agreement on Labials, Place Agreement on Dorsals, and Voicing Agreement within ABC. Corr constraints for individual features demand correspondence for segments having those features, and id-cc.place demands place agreement for segments in correspondence. For PAD, which is asymmetric, there is an ad hoc Corr constraint, Corr.[dor]/C2=[lab], that demands correspondence from only a subset of dorsal pairs. Directional input/output place faithfulness constraints allow for the complex agreement candidate to be preferred. The place co-occurrence restrictions in Ngbaka are thus modeled as an instance of long-distance place agreement.

\section{Significance of complex place}

Complex place is crucial for detecting place harmony based on place similarity. If two homorganic segments are in correspondence, then they by definition satisfy id-cc.place. Semihomorganic consonant pairs, however, are similar enough to be in correspondence (in that they share a place feature), but not similar enough to satisfy place identity (due to the unshared place feature).

Bennett 2013 does make use of a id-cc.place constraint, as part of a larger analysis of Complete Identity Effects. In discussing the alleged absence of major place hamony, he calls it a "plausible accidental gap", detailing the set of circumstances required to make visible major place harmony. He states that "[m]ajor place harmony would only be conclusively identifiable as such if it cuts across different manners of articulation" (Bennett 2013: 317). However, this is not considering the possibility of complex place. Bennett does discuss languages with similar patterns, such as a process in Ponapean involving $[\mathrm{p}]$ and $\left[\mathrm{p}^{\mathrm{w}}\right] /\left[\mathrm{p}^{\mathrm{V}}\right]$ (see also Hansson 2010), but uses a surface identity constraint for the ad hoc feature [labio-velar] instead of one for place directly. Cahill 2006 cites Kukú and Kaanse as two other languages (in addition to Ngbaka) which exhibit patterns 
similar to PAL with labial-dorsals. These languages would have a similar analysis as here if the patterns are robust, and could be further instances of major place harmony.

Furthermore, the representation of the complex segment itself is less crucial in the analysis here. In Sagey's analysis of Ngbaka ma'bo, the labial articulator of the labial-dorsal was marked as primary, and the co-occurrence restriction only holds between two primary articulators (Sagey 1986: (109)). This distinction is made with a "pointer" device that acts as a diacritic on a particular place feature. Other representational devices that have been used to represent abstract primary place are surveyed in van de Weijer 2011. None of them are needed here, as asymmetries between labial and dorsal interactions are captured through both the ranking and the constraint defintions. PAL applies because of the ranking of Corr.[labial]. PAD doesn't apply to $\widehat{\mathrm{KP}}$...K pairs due to the ranking of Corr.[dorsal]. The ad hoc constraint Corr.[dor]/C2=[lab] is necessary to demand correspondence on $\mathrm{K} . . . \widehat{\mathrm{KP}}$, but again, there is no difference in the segmental representation of any of these segments with respect to place.

\section{Conclusion}

Place co-occurrence restrictions in Ngbaka are instances of major place harmony. Labial pairs, and certain dorsal pairs, correspond, and agree for place. These patterns are supported by a new digitization and analysis of a Ngbaka dictionary (Maes 1959). Complex segments like the doubly-articulated stops $[\overline{\mathrm{kp}}]$ and $[\overline{\mathrm{gb}}]$ are crucial to clearly seeing the effects of id-cc.place. Asymmetries in the treatment of complex segments to simple segments is captured via the constraint ranking and definitions rather than through representational devices marking abstract primary place.

Because both dissimilation and agreement analyses in $\mathrm{ABC}$ require id-cc.place to dominate id-io.place, a fixed universal ranking of id-io.place $\gg$ id-cc.place, or elimination of id-cc.place altogether, is not feasible (cf. Rose \& Walker 2004: 520, Gallagher \& Coon 2009). Place harmony is also extremely common in child language (see Goad 1997, Levelt 2011 and references therein), so perhaps it is not surprising to find it in the typology of long-distance consonant agreement as well.

\section{A Supplementary materials}

Annotated documents containing the full wordlist and statistical results as well as the full ranking calculations are available as supplementary materials at http://nickdanis.com/ngbaka.

\section{References}

Agresti, Alan. 2007. An Introduction to Categorical Data Analysis. 2nd edn. Hoboken, New Jersey: John Wiley \& Sons.

Bennett, Wm G. 2013. Dissimilation, Consonant Harmony, and Surface Correspondence. Rutgers University dissertation.

Bennett, Wm G. 2014. Some differences between clicks and labio-velars. South African Journal of African Languages 34. 115-126.

Cahill, Michael. 1999. Aspects of the phonology of labial-velar stops. Studies in African Linguistics 28. 155184.

Cahill, Michael. 2000. Positional Contrast and Labial-Velars. OSU Working Papers in Linguistics.

Cahill, Michael. 2006. The Place of Labial-Velars. Annual Conference on African Linguistics. Eugene, OR.

Coetzee, Andries W. \& Joe Pater. 2008. Weighted constraints and gradient restrictions on place co-occurrence in Muna and Arabic. Natural Language \& Linguistic Theory 26(2). 289-337.

Connell, Bruce. 1994. The structure of labial-velar stops. Journal of Phonetics 22. 441-476.

Danis, Nick. N.d. Phonological Effects of Semihomorganicity: Studies in Complex Place. In progress. Rutgers University dissertation.

Danis, Nick. 2014. Deriving Interactions of Complex Stops. ROA-1220.

Danis, Nick. 2017. Markedness and complex stops: Evidence from simplification processes. In Proceedings of the 8th World Congress of African Languages. ILCAA, Tokyo University of Foreign Studies.

Frisch, Stefan A. 2011. Frequency Effects. In Marc van Oostendorp, Colin J. Ewen, Elizabeth Hume \& Keren Rice (eds.), The Blackwell Companion to Phonology, vol. 4, 5 vols. Wiley-Blackwell. 
Gallagher, Gillian \& Jessica Coon. 2009. Distinguishing Total and Partial Identity: Evidence from Chol. Natural Language \& Linguistic Theory (3). 545.

Goad, Heather. 1997. Consonant harmony in child language: an optimality theoretic account. In S.J. Hannahs \& Martha Young-Scholten (eds.), Focus on Phonological Acquisition, 113-142. Amsterdam/Philadelphia: John Benjamins.

Hansson, Gunnar. 2010. Consonant Harmony: Long-Distance Interaction in Phonology. Berkeley: University of California Press.

Henrix, Marcel, Karel van den Eynde \& Michael Meeuwis. 2007. Description grammaticale de la langue Ngbaka: phonologie, tonologie, et morphosyntaxe. OCLC: 166214567. München: LINCOM Europa.

Iacoponi, Luca. 2016. Fixed Ranking over Stringency. Poster presented at AMP 2016. University of Southern California.

Ladefoged, Peter. 1968. A Phonetic Study of West African Languages. Cambridge University Press.

Ladefoged, Peter \& Ian Maddieson. 1996. The Sounds of the World's Languages. Blackwell Publishing.

Levelt, Clara C. 2011. Consonant Harmony in Child Language. In Marc van Oostendorp, Colin J. Ewen, Elizabeth Hume \& Keren Rice (eds.), The Blackwell Companion to Phonology, vol. 3, 1691-1716. WileyBlackwell.

Lewis, M. Paul. 2009. Ethnologue: Languages of the World, Sixteenth edition. Dallas, TX: SIL International. Online version: http://www.ethnologue.com/.

Maes, Védaste. 1959. Dictionnaire Ngbaka-Francais-Neerlandais. Tervuren: Commissie voor Afrikaanse Taalkunde / la Commission de Linguistique Africaine.

McCarthy, John \& Alan Prince. 1995. Faithfulness and Reduplicative Identity. In Jill Beckman, Suzanne Urbanczyk \& Laura Walsh Dickey (eds.), University of Massachusetts Occasional Papers in Linguistics 18: Papers in Optimality Theory, 249-384. Amherst, MA: GLSA.

Mester, Armin. 1986. Studies in Tier Structure. University of Massachusetts Amherst dissertation.

Padgett, Jaye. 1995. Partial Class Behavior and Nasal Place Assimilation. In Proceedings of the Arizona Phonology Conference: Workshop on Features in Optimality Theory. Tucson, AZ: University of Arizona Department of Linguistics.

Padgett, Jaye. 2002. Feature Classes in Phonology. Language 78. 81-110.

Pater, Joe. 1999. Austronesian Nasal Substitution and other NC effects. In The Prosody Morphology Interface. Cambridge University Press. Pre-print version. ROA-160. Accessed 17 July 2014.

Pierrehumbert, Janet. 1993. Dissimilarity in the Arabic Verbal Roots. In Proceedings of the North East Linguistic Society 23, University of Ottawa. UMass Amherst: GSLA.

Pouplier, Marianne, Larissa Chen, Louis Goldstein \& Dani Byrd. 1999. Kinematic evidence for the existence of gradient speech errors. The Journal of the Acoustical Society of America 106(4). 2242.

Prince, Alan. 2002. Arguing Optimality. In Papers in Optimality Theory II.

Prince, Alan, Bruce Tesar \& Nazarré Merchant. 2016. OTWorkplace.

Rose, Sharon \& Rachel Walker. 2004. A Typology of Consonant Agreement as Correspondence. Language 80. 475-531.

Sagey, Elizabeth. 1986. The Representation of Features and Relations in Non-Linear Phonology. Massachusetts Institute of Technology dissertation.

Sharpe, Donald. 2015. Your Chi-Square test is statistically significant: now what? Practical Assessment, Research \& Evaluation 20(8).

Shaw, Patricia A. 1991. Consonant harmony systems: the special status of coronal harmony. In Carole Paradis \& Jean-François Prunet (eds.), The Special Status of Coronals: Internal and External Evidence, 125-157. DOI: 10.1016/B978-0-12-544966-3.50013-0. Academic Press.

Thomas, Jacqueline M. C. 1963. Le Parler Ngbaka de Bokanga: Phonologie, Morphologie, Syntaxe. Paris: Mouton \& Co.

Walker, Rachel. 2001. Consonantal correspondence. In Robert Kirchner, Joe Pater \& Wolf Wikeley (eds.), Proceedings of the Workshop on the Lexicon in Phonetics and Phonology. Papers in Experimental and Theoretical Linguistics, vol. 6, 73-84. Edmonton: Department of Linguistics, University of Alberta.

van de Weijer, Jeroen. 1996. Segmental Structures and Complex Segments. Tübingen: Max Niemeyer Verlag. van de Weijer, Jeroen. 2011. Secondary and Double Articulation. In Marc van Oostendorp, Colin J. Edwards, Elizabeth Hume \& Keren Rice (eds.), The Blackwell Companion to Phonology. John Wiley \& Sons. 